\title{
NIETZSCHE E DERRIDA EM TORNO DO PATHOS DO PERDÃo ${ }^{1}$
}

\author{
Jorge Luiz Viesenteiner ${ }^{2}$ \\ Universidade Federal do Espírito Santo (UFES) \\ https://orcid.org/0000-0003-3727-7890 \\ Lucas Fraga Gomes ${ }^{3}$ \\ Universidade Federal do Espírito Santo (UFES) \\ https://orcid.org/0000-0001-9179-6726
}

\begin{abstract}
RESUMO:
O objetivo do artigo é analisar a aproximação temática do pathos do perdão em Nietzsche e Derrida, vinculando ambos os autores por meio do registro teórico da extramoralidade do perdão. A tese a se sustentar é que tanto Nietzsche quanto Derrida explicam o tema do pathos do perdão, por um lado, em um horizonte em que não cabem mais as ferramentas do cálculo ou da normalização para investigar o perdão, na medida em que esse conceito tem de ser situado para além da esfera moral, jurídica, religiosa, ou mesmo da justiça punitiva e, por outro lado, distanciam-se de uma tradição reconciliatória em proveito de uma práxis de diferenciação. Para isso, o texto percorre dois movimentos: por um lado, a problematização do tema em Nietzsche, enfatizando a estratégia argumentativa da genealogia e a figura de pensamento do indivíduo soberano e, por outro lado, a herança nietzscheana para Derrida e suas aproximações com o tema do perdão.
\end{abstract}

PalavRaS-ChAVE: Perdão; Graça; Autossupressão; Diferenciação.

\section{NIETZSCHE AND DERRIDA ON FORGIVENESS'S PATHOS}

\begin{abstract}
:
The article aims to analyze the thematic approach of the of forgiveness's pathos by Nietzsche and Derrida, connecting both authors through the theoretical aspect of extra-morality of forgiveness. We sustained that both Nietzsche and Derrida explain the forgiveness's pathos, on the one hand, from a horizon in which calculation or normalization is not more adequate, in order to investigate forgiveness, insofar as forgiveness has to be situated beyond moral, juridical, religious, or even punitive justice sphere; on the other hand, both of them take distance from a reconciliatory tradition in favor of a differentiation's praxis. For this goal, the text goes through two movements: on the one hand, we explain how Nietzsche works up the issue, emphasizing the argumentative strategy of genealogy and the figure of thought of the sovereign individual and, on the other hand, the Nietzschean inheritance for Derrida and approximations of the Algerian Philosopher with the forgiveness theme.
\end{abstract}

KEYWORDS: Frgiveness; Mercy; Self-overcoming; Differentiation;

\footnotetext{
${ }^{1}$ Esta pesquisa é financiada pelo CNPq, contemplada com bolsa de pesquisa por meio do Edital Universal MCTI/CNPq 14/2014, com vigência até o final de 2017. Esse artigo é também o resultado de discussões que foram iniciadas em outubro de 2014 durante o "I Congresso do Núcleo de Estudos Nietzschianos da UFPR", e que teve como tema justamente "As fronteiras do perdão e da justiça". Agradeço a interlocução naquela ocasião.

2 Doutor em Filosofia pela Universidade de Campinas (UNICAMP), São Paulo - Brasil. Professor do Departamento de Filosofia e do Programa de Pós-graduação em Filosofia da Universidade Federal do Espírito Santo (UFES), Espírito Santo - Brasil. Email: jvies@uol.com.br

3 Mestrando do Programa de Pós-graduação em Filosofia da Universidade Federal do Espírito Santo (UFES), Espírito Santo - Brasil. Email: lucasfragagomes@gmail.com
}

VIESENTEINER, Jorge Luiz; GOMES, Lucas Fraga. Nietzsche e Derrida em torno do pathos do perdão. Griot : Revista de Filosofia, Amargosa, Bahia, v.16, n.2, p.352-370, dezembro/2017. 


\section{Introdução}

Muito sabemos sobre as relações entre Nietzsche e Derrida no que se refere, p.ex., ao tema dos "estilos". Quanto a temáticas como perdão, contudo, são mais escassas as análises, em que pese a forte herança que Derrida recebeu de Nietzsche inclusive para refletir sobre a questão. Esse artigo se propõe justamente realizar a aproximação entre ambos os autores, em torno de uma temática que é mais clara e direta em Derrida, mas não tão óbvia para Nietzsche. Isso se explica porque, como se sabe, Derrida tematizou direta e mais frequentemente o perdão em seus textos, conforme veremos, a propósito do seu debate à época da Comissão da Verdade e da Reconciliação na África do Sul. Nietzsche, por outro lado, nunca problematizou em específico o perdão, mas na referência que vamos analisar nesse artigo especialmente o aforismo 10 da Segunda Dissertação de Para genealogia da moral empregou a expressão "graça" (Gnade). Nossos esforços serão dirigidos no artigo, porém, justamente para indicar a estreita aproximação nos autores, sobretudo se pensamos o perdão não mais na esfera política, jurídica, religiosa ou moral, mas sim no horizonte do que denominamos de "pathos" do perdão. Por pathos compreendemos aqui um contraconceito da razão, ou seja, um conceito que não pode ser conceitualizado tal como conceitualizamos normalmente um conceito, pois tão logo assim procedemos, o objeto de investigação se torna definível e calculável. Como pathos, pois, o perdão é igualmente um conceito que tem de ser analisado para além do horizonte calculativo e definível e, como tal, em um horizonte extramoral. É nessa instância que fazemos a vinculação de ambos os autores.

O problema nuclear a ser investigado em se tratando do perdão, ou ainda de certa tradição com a qual o tema do perdão está relacionado, consiste em desvelar ou exercer uma "crítica" direcionada a dois horizontes: por um lado, o perdão é tradicionalmente abordado a partir do horizonte moralizador, ou seja, tratado sempre no interior da esfera moral que tenta encontrar o equivalente ao dano, ao crime, à ofensa, desdobrando a economia do castigo ou da justiça punitiva e a consequente restauração do status quo, a fim de que o perdão seja possível - lógica essa que se legaliza historicamente até atingir a publicização do perdão após a II Guerra. Nessa esfera, o perdão é ainda subsumível a um fator moral, jurídico, religioso, etc.; por outro lado, essa mesma moralização do conceito de perdão também se insere numa certa ideia de história pautada na reconciliação, cujo circuito moral vai do passado (a culpa transformada em pecado), passando pelo presente (a confissão e o arrependimento) até atingir a perspectiva de futuro (marcada pela reconciliação/redenção), e que tem no cristianismo o fiel depositário dessa economia reconciliatória. A tratativa do perdão nesse artigo pressupõe situá-lo para além desses dois horizontes moralizadores, seja da moralização do próprio valor perdão, seja da tradição reconciliatória em que está inserido. Para isso, o artigo percorre dois movimentos teóricos, um dedicado ao tema em Nietzsche e outro dedicado a Derrida, com uma breve finalização teórica das vinculações entre os autores.

A hipótese de trabalho do primeiro movimento do texto é mostrar que Nietzsche leva às últimas consequências o problema da moralização e da reconciliação, a fim de reconhecer que em tais situações limítrofes o perdão se desloca das possibilidades moralizantes/reconciliadoras, tornando-se impossível compreendê-

VIESENTEINER, Jorge Luiz; GOMES, Lucas Fraga. Nietzsche e Derrida em torno do pathos do perdão. Griot : 
lo por meio de quaisquer perspectivas conceituais/morais, mas antes situando-o no horizonte de um contraconceito à razão, ou ainda, como dissemos acima, o perdão como pathos. Justamente por isso Nietzsche nunca emprega o termo perdão como conceito filosófico, mas sim o termo "graça" (Gnade) em sua Genealogia. O objetivo central desse primeiro movimento, portanto, é analisar em que medida o perdão atinge suas regiões limítrofes, tão logo o suspendemos de uma tratativa moralizante ou reconciliatória, e não apenas refutá-lo no interior da própria lógica da moralização/reconciliação, pois essa refutação ainda seria mais uma de suas possibilidades moralizadoras. $\mathrm{O}$ conceito-chave para indicar esse deslocamento é a noção de "diferenciação". No segundo movimento do texto, arriscamos uma breve aproximação com a abordagem de Derrida sobre o perdão, notadamente quando o analisa por meio da noção de "impossível", ou seja, somente quando o perdão se torna impossível e, igualmente, para além das esferas reconciliatórias ou moralizantes, é que recebe novamente a dignidade da qual sempre o acompanhou.

\section{Primeiro movimento: Nietzsche em torno do pathos do perdão Genealogia como exercício "crítico"}

A elaboração do tema da "graça" ocorre no aforismo 10 da Segunda Dissertação da Genealogia da moral, associada também ao conceito de "autossupressão" (Selbstaufhebung) da justiça. A nosso ver, esse aforismo exprime bem a tese da de-moralização (entmoralisierung) de um conceito moral, a fim de passar a compreendê-lo em um sentido extramoral, ou seja, para além de um registro moralizante, jurídico, político, etc., capaz de explicar como Nietzsche costumeiramente entende um conceito a partir de sua semântica totalmente deslocada, tal como é o caso para a relação entre perdão e graça.

O instrumento crítico que orienta esse exercício de de-moralização é precisamente o conceito de genealogia, que por sua vez tem de ser entendido não apenas como uma "história do surgimento", mas sim em seu registro "crítico" (GC 345; KSA 3, p. 578). ${ }^{4}$ O exercício da genealogia como "crítica" ${ }^{5}$ consiste, sem dúvida, em pôr em questão o valor do valor perdão, mas principalmente em problematizar aquilo que se tornou demasiado evidente no interior da história do perdão e da tradição reconciliatória em que ele está inserido, e que, justamente por se tornar demasiado cristalizado, não consegue mais ser trazido à tona e problematizado naquilo que é medular nele: sua moralização no interior de uma tradição e sua tratativa em torno da reconciliação. Questionar o valor do valor perdão, nesse caso, tem de pressupor abordá-lo no interior do argumento genealógico, bem como

\footnotetext{
${ }^{4}$ As obras de Nietzsche são citadas conforme a edição crítica: NIETZSCHE, F. Sämtliche Werke. Kritische Studienausgabe in 15 Bänden. (KSA) Hrsg. Giorgio Colli und Mazzino Montinari. Berlin/New York: DTV \& Walter de Gruyter, 1999. Utilizamos as seguintes referências já consolidadas para os textos de Nietzsche, aos livros citados: Para as referências de obras enviadas para publicação de Nietzsche, segue-se a abreviação do livro (GC: A gaia ciência; ABM: Para além de bem e mal; GM: Para genealogia da moral; CW: $O$ caso Wagner; EH: Ecce homo), número do aforismo e referência nas obras completas KSA, com seu respectivo volume e número de página (p.ex., ABM 257; KSA 5, p. 205; EH, Crepúsculo dos ídolos 2; KSA 6 , p. 355, etc.). Todas as traduções são de nossa própria autoria.

5 Cf. STEGMAIER, W. Nietzsches „Genealogie der Moral“. Darmstadt: WGB, 1994, p. 66: “Genealogia como crítica ao invés de história é a crítica das aparentes autoevidências da moral, por meio de um contínuo esboço hipotético sobre sua proveniência."
}

VIESENTEINER, Jorge Luiz; GOMES, Lucas Fraga. Nietzsche e Derrida em torno do pathos do perdão. Griot : Revista de Filosofia, Amargosa, Bahia, v.16, n.2, p.352-370, dezembro/2017. 
empregando-o em seu registro crítico. Esse registro da genealogia nos permite ampliar seu emprego para além do aspecto moral, deslocando-o também ao horizonte da crítica à metafísica ( $\mathrm{ABM} 1$ ), ou mesmo de um exercício autogenealógico (GC $346){ }^{6}$

\section{A estratégia crítica do argumento genealógico}

Acrescente-se ao registro crítico da genealogia uma ferramenta fundamental para compreender a estratégia de deslocamento que Nietzsche opera, e que vai do perdão até a noção de graça, a saber, a estratégia de "diferenciação". Essa estratégia tem por função, além disso, explicar em que sentido Nietzsche radicaliza a abordagem de um conceito moralizado, para então considerá-lo em um sentido extramoral. Para compreender essa ferramenta e sua função na estratégia genealógica de deslocamento, vamos nos concentrar nos três primeiros aforismos da Segunda Dissertação de Para genealogia da moral, e apontar dois horizontes de compreensão: por um lado, o argumento genealógico nunca é autoconstitutivo, mas é construído sempre por meio de diferenciações, seja de interlocutores, perspectivas tradicionais, ironizações, dramatizações por meio de construção de tipos psicológicos, figurações, etc.; por outro lado, o "indivíduo soberano" é a figura de pensamento por meio da qual Nietzsche potencializa essa diferenciação, mas principalmente porque é por meio dele que compreendemos o processo de de-moralização ou extramoralização - ou o sentido em que um conceito moral atinge seu limite -, visto que ele é "supramoral"; além disso, o indivíduo soberano é uma figura que está associada com outras noções de Nietzsche, como o conceito de "nobreza", e que tem como dinâmica mais própria seu contínuo exercício diferenciador.

\section{Estrutura do argumento genealógico: estratégia de diferenciação}

Passamos agora a esboçar alguns elementos constitutivos da estratégia de diferenciação da genealogia. ${ }^{7}$

a) A práxis interrogativa. Nietzsche inicia a 'segunda dissertação' com uma fulminante interrogação que já desloca as tradicionais abordagens da promessa, vinculadas à cultura: "Criar um homem a quem seja permitido prometer - não é essa a tarefa paradoxal que a natureza se impôs em relação ao homem? Não é este o verdadeiro problema do homem?" (GM II 1; KSA 5, p. 291)

A práxis interrogativa tem a função de denunciar justamente aquilo que está demasiado óbvio no interior de um processo, bem como forçar, performaticamente, a inclusão de um interlocutor em relação às hipóteses que Nietzsche esboça. A práxis da interrogatividade compõe propriamente o núcleo do aforismo 6 do 'Prólogo' de Para genealogia da moral, igualmente construído com os vários empregos do radical

\footnotetext{
${ }^{6}$ Para um detalhamento e amplitude desse registro teórico, ef. VIESENTEINER, Jorge L. "Estrutura formal e semântica do argumento autogenealógico". In: Cadernos de filosofía alemã v. 20, n. 2 (2015), pp. 105-119.

7 Sobre o tema e a estrutura discursiva do argumento genealógico, cf. SAAR, M. Genealogie als Kritik. Geschichte und Theorie des Subjekts nach Nietzsche und Foucault. Frankfurt/New York: Campus Verlag, 2007.
}

VIESENTEINER, Jorge Luiz; GOMES, Lucas Fraga. Nietzsche e Derrida em torno do pathos do perdão. Griot : 
Fragen, bem como a colocação mesma de contínuas interrogações. A práxis interrogativa, nesse caso, força o argumento ao seu limite, envolvendo o leitor na argumentação, tão logo ele é confrontado com as perguntas que, por sua vez, exercem a função de problematizar o que se tornou cristalizado.

b) Subversões de vocabulário. A subversão é percebida por meio da confrontação provocativa que Nietzsche faz entre a tarefa da "cultura" e a tarefa da "natureza": uma inversão estratégica daquela clássica tarefa cultural que consistiria em produzir alguém capaz de prometer. Nesse caso, não se trata da cultura, mas uma tarefa que a "natureza se impôs", para "cultivar" [heranzüchten] um "animal" (Thier) a quem seja "permitido prometer" [versprechen darf] e "responder por si como futuro" [für sich als Zukunft gut sagem zu können], ou seja, Nietzsche põe no centro do debate um caríssimo conceito para a tradição contratualista, a promessa, a fim de subvertê-lo estrategicamente e realizar a sua própria 'história natural da moral e da razão'. O vocabulário empregado por Nietzsche é claramente provocativo 'natureza', 'cultivo', 'animal', que são termos antagônicos às tarefas da cultura, mas que, porém, põem-se à tarefa de construir esse animal que 'promete' e dispõe de si no futuro -, para forçar os limites da própria tradição contratualista elaborada pela cultura - que me parece estar em jogo aqui também, tal como a Segunda Dissertação continua -, cujo argumento genético para a promessa, a tensão entre esquecimento e memória, isto é, a "força inibidora ativa" do esquecimento e um "ativo não mais querer livrar-se" de uma saudável "memória da vontade", torna-se irreconciliável nessa subversão.

Nesse caso, o próprio vocabulário crítico de Nietzsche - natureza, animal, cultivo - já tem de ser entendido como contramovimento diferenciador e, simultaneamente, subversivo em relação ao trabalho daquela outra tradição conciliatória do contrato, com seus empregos, respectivamente, cultura, homem e racionalidade. De qualquer modo, trata-se de uma estratégia de subversão que não sobrevive sem uma outra tradição, ou seja, não é autoconstitutiva, e contra a qual a subversão tem de se diferenciar.

c) Interlocutores. $\mathrm{O}$ argumento genealógico é construído continuamente por meio de interlocutores. Isso significa que o argumento genealógico não pode prescindir de um interlocutor externo, em torno do qual, contra o qual, enfim, a hipótese genealógica se estrutura. Isso reforça a tese de que a genealogia nunca é autoconstitutiva, mas só consegue estruturar hipóteses parasitariamente em relação a um interlocutor. Essa relação parasitária a algo e, portanto, absolutamente dependente desse algo externo, é justamente aquilo contra o qual a hipótese genealógica tem de se diferenciar. No caso dos aforismos 1 e 2 da Segunda Dissertação, os interlocutores são as hipóteses utilitaristas e seus correlatos, tal como ele menciona em Para além de bem e mal, livro este que não pode deixar de ser lido ao lado da Genealogia: "Seja hedonismo, seja pessimismo, seja utilitarismo ou seja eudaimonismo: todas essas formas de pensar que medem o valor das coisas segundo o prazer $[$ Lust] e a dor [Leid], isto é, conforme estados concomitantes e questões secundárias, são formas de pensar de fachada e ingenuidades" (ABM 225; KSA 5, p. $160)$.

Ora, na Genealogia a premissa psicológica de Nietzsche igualmente lança mão do conceito de Leid, mas é preciso distinguir ali entre dois sentidos de Leid: aquele 
contra o qual o utilitarismo usualmente situa o prazer, e aquele vinculado ao imenso trabalho da "pré-história da moral", e que consiste em tornar o homem, primeiramente, "calculável, constante, necessário", como é posição assumida por Nietzsche: "Quanto o homem teve primeiramente que aprender, a fim de dispor dessa maneira do futuro, a separar o acontecimento necessário daquele causal, a pensar de maneira causal, a ver e antecipar o que está distante como algo atual, a estabelecer com segurança o que é fim e o meio para esse fim, a poder calcular e contar, - para isso, quanto o homem teve antes de se tornar ele mesmo calculável, constante e necessário também para si mesmo em sua própria representação, a fim de que, dessa maneira, tal como faz alguém que promete, poder responder por si mesmo como futuro!" (GM II 1; KSA 5, p. 292) Esse sentido da "dor" é aquele da "mnemotécnica" que acompanha a longa "pré-história da moral', como escreve Nietzsche, pois "apenas o que não cessa de causar dor permanece na memória." (GM II 3; KSA 5, p. 295). A construção por diferenciação da sua própria posição culmina, como escreve Nietzsche em Para além de bem e mal, justamente na ironização das hipóteses 'utilitaristas": "há problemas mais elevados do que qualquer problema sobre dor, prazer e compaixão; e qualquer filosofia que se concentre apenas nisso é ingenuidade." (ABM 225; KSA 5, p. 161) ${ }^{8}$

d) Epocalizações. Nietzsche constrói epocalizações para elaborar sua hipótese, do mesmo modo como procedem as hipóteses contratualistas, ao epocalizarem a gênese das relações contratuais. No caso dos aforismos iniciais da Segunda Dissertação de GM, a tarefa de cultivar um animal a quem seja 'permitido prometer' também é hipoteticamente epocalizada, de modo a remontar a uma "pré-história" da moral, ou aquilo que Nietzsche já havia denominado de "moralidade dos costumes", cujo fruto maduro é precisamente a figura de pensamento intitulada "indivíduo soberano". 9

A estratégia da epocalização também já estava registrada no aforismo 32 de Para além de bem e mal, cuja tentativa de determinação genética do valor da ação partia de uma "pré-história" da moral - em que o valor da ação estava na consequência - passando pela época "moral" - em que "interpretou-se a origem de uma ação no sentido mais determinado, como origem a partir de uma intenção" - até a epocalização denominada por Nietzsche de "extramoral" (aussermoralisch), momento culminante desse desdobramento, quando Nietzsche curiosamente encena a si mesmo como "imoralista", a fim de desvelar aquilo que na tradição genética da moral havia se cristalizado como preconceito, a saber, a própria "intenção". O período 'extramoral' é o ponto de culminância da epocalização, quando não nos é mais lícito avaliar e julgar algo a partir do metro das epocalizações precedentes, ou

\footnotetext{
8 A estratégia da construção de hipóteses a partir de uma narrativa constituída por diferenciações também é encontrada quando Nietzsche constrói a hipótese da vontade de poder, por meio da diferenciação relativamente à 'regularidade dos físicos' em ABM 22, especialmente quando ali Nietzsche, encenado como 'velho filólogo', cita entre aspas uma certa interpretação da natureza como 'vontade de poder', de modo a diferenciar-se, estrategicamente, na explicação mecanicista. Sobre essa autoencenação como "velho filólogo" e sua importância teórica, cf. BORN, M. "Nietzsches rhetorische Inszenierung der Psychologie". In: GEORG, J.; ZITTEL, C. (Hrsg.). Nietzsches Philosophie des Unbewussten. Berlin/Boston: Walter de Gruyter, 2012, pp. 197-206. Além disso, para uma relação entre crítica da cultura e ironizações, cf. Giacoia, O. "Kulturkritik und Satyrspiel bei Nietzsche". In: Nietzscheforschung, v. 23 (2016), pp. 319-324.

9 Sobre esse ponto, cf. Höffe, O. "Ein Thier heranzüchten, das versprechen darf". In: Höffe, O. (Hrsg.). Zur Genealogie der Moral. Bd. 29. Berlin: Akademie Verlag, 2004. pp. 65-79.
}

VIESENTEINER, Jorge Luiz; GOMES, Lucas Fraga. Nietzsche e Derrida em torno do pathos do perdão. Griot : Revista de Filosofia, Amargosa, Bahia, v.16, n.2, p.352-370, dezembro/2017. 
seja, a 'consequência' do período pré-moral ou a 'intenção' do período moral. Chamamos atenção para o fato de que Nietzsche se autodenomina 'imoralista' nesse período 'extramoral' de ABM 32, justamente porque leva às últimas consequências a tese da epocalização, mostrando que, no limite, os juízos morais precedentes só podem aparecer como injustos ou imperdoáveis. $O$ recurso epocal objetiva, heuristicamente, mostrar o limite do próprio juízo moral, de modo que o 'imoralista' assume juízos morais não mais em sua semântica usual, mas em sentido extramoral.

Registramos ainda que esse mesmo exercício de crítica nietzscheano que o permite desvelar ou pôr a nu justamente aquilo que se tornou demasiado evidente no interior do processo de moralização, a saber, o fato de que, como ele escreve, "a moral das intenções foi um preconceito, uma precipitação e talvez uma provisoriedade [...]" é, simultaneamente, o exercício que o faz se autodiferenciar, agora como imoralista, em uma época 'extramoral', a fim de empregar igualmente uma fórmula moral em um sentido extramoral: a autossuperação da moral [die Selbstüberwindung der Moral]: “A superação da moral, e em um determinado sentido até mesmo a autossuperação da moral: esse poderia ser o nome para aquele longo e secreto trabalho que ficou reservado às consciências mais sutis e mais probas, mas também às consciências mais maliciosas de hoje" (ABM 32; KSA 5, p. 50s.).

e) A função do 'indivíduo soberano'. Se em Para além de bem e mal é o imoralista que se autodiferencia em uma época 'extramoral', no aforismo 2 da Segunda Dissertação de Para genealogia da moral a figura de pensamento remonta ao "indivíduo soberano", resguardando a mesma estratégia de epocalização. O longo trabalho da moralização dos costumes da hipótese 'pré-histórica' alcança o fruto maduro desse processo por meio de um Typus que exprime a mesma perspectiva extramoral de ABM, a saber, aquele que é "igual apenas a si mesmo, novamente liberado da moralidade do costume, indivíduo autônomo e supramoral [das autonome übersittliche Individuum] (pois 'autônomo' e 'moral' se excluem)", justamente aquele indivíduo a quem é 'permitido prometer' ${ }^{10} \mathrm{O}$ indivíduo soberano é soberano não mais sobre outros ou algo, mas soberano apenas sobre si mesmo e, na medida em que está novamente liberado da 'moralidade dos costumes', tornou-se extramoral ou 'supramoral e autônomo'. Quando Nietzsche escreve que 'autônomo' e 'moral' se excluem é justamente porque não é mais lícito empregar o metro moral da moralidade dos costumes para julgamento e avaliação da figura de pensamento como o indivíduo soberano. Se esse indivíduo é radicalmente autônomo, não o é mais em sentido moral, mas sim 'supramoral' porque 'liberado novamente da moralidade dos costumes', de modo que compreendemos novamente uma fórmula moral empregada por Nietzsche em sentido extramoral, ou seja, a práxis de autossupressão do conceito moral de 'autonomia', empregado agora em sentido extramoral.

A perspectiva 'aussermoralisch' do 'imoralista' em ABM 32 tem estreita conexão, do ponto de vista da estratégia da epocalização, com a perspectiva 'supramoral' (übersittlich) da figura do 'indivíduo soberano' em GM, e igualmente coincidem no tocante ao indicativo do limite de um certo processo moral, seja da 'moral da intenção' em ABM, seja da promessa da tradição contratualista em GM, cuja condição limítrofe é justamente a autodiferenciação operada por Nietzsche

10 Para uma explicação mais detalhada da tese de que 'autônomo' e 'moral' se excluem, cf. Giacoia, O. “Zu Nietzsches Satz 'autonom und sittlich schliesst sich aus"”. In: Nietzsche-Studien, v. 40 (2011), pp. 156-177.

VIESENTEINER, Jorge Luiz; GOMES, Lucas Fraga. Nietzsche e Derrida em torno do pathos do perdão. Griot : Revista de Filosofia, Amargosa, Bahia, v.16, n.2, p.352-370, dezembro/2017. 
como 'imoralista' ou como 'indivíduo soberano' que não podem mais ser medidos por aquilo por meio do qual eles são diferentemente encenados. $\mathrm{O}$ imoralista 'extramoral' ou o indivíduo soberano 'supramoral' não são mais subsumíveis, medidos ou avaliados pelo horizonte moral do qual eles são encenados como diferenciados. Ambas epocalizações compreendem um processo que não é guiado cognitivamente, mas afetivamente por meio da dor, da mnemotécnica, sangue, martírio, até se tornar "instinto, instinto dominante", aquele "privilégio extraordinário da responsabilidade." (GM II 2)

Em cada uma dessas estratégias próprias do argumento genealógico há sempre um algo por meio do qual Nietzsche constrói, parasitariamente, uma hipótese por meio da diferenciação. Nossa ênfase aqui está em reconhecer que tal estratégia de diferenciação é constitutiva do próprio argumento genealógico, de modo que não é possível prescindir dessas peculiaridades comunicativas, certificando-se que a estratégia mesma como tal já constitui, ela própria, não apenas um mero adorno estilístico, mas sim um argumento.

A estratégia de diferenciação na construção do argumento genealógico implica em abandonar as possibilidades de avaliação moral, desde o instrumental conceitual da tradição ou da instância contra a qual Nietzsche tenta diferenciar seu argumento, de modo que compreendemos em que medida uma certa tradição é levada às suas últimas consequências, ali onde a própria tradição já não é mais medida e nem mesmo é capaz de exercer a função de normalização ou instrumento avaliativo, autossuprimindo-se. Trata-se então de um processo de de-moralização do valor do moral do perdão, a partir da própria tradição que moraliza o perdão mesmo.

Ao se referir ao conceito de 'graça' no aforismo 10 da Segunda Dissertação da Genealogia, Nietzsche não emprega o conceito moral "perdão", mas "autossupressão da justiça", a autossupressão daquela justiça punitiva. É preciso compreender, contudo, que o ponto de culminância desse processo no interior do Estado é análogo ao ponto de culminância daquele processo de moralização dos costumes expresso sob a figura do indivíduo soberano, de modo que a autossupressão da justiça é análoga ao "Estado que se torna soberano": "segundo Nietzsche, um Estado soberano comporta-se tal como o indivíduo soberano. [...] O Estado é soberano no sentido de Nietzsche, quando pode permitir existir indivíduos soberanos, e os indivíduos são soberanos quando permitem o Estado." (STEGMAIER, 1994, p. 148s.) Nesses termos, pois, compreende-se porque Nietzsche emprega autossupressão da justiça, uma vez que a argumentação é sobre o ponto de culminância em que a justiça punitiva se autossuprime no interior do Estado. Entretanto, continua Nietzsche, "graça" é o "privilégio dos mais poderosos, ou melhor, seu além do direito" (GM II 10; KSA 5, p. 309), justamente quando, para esses 'mais poderosos' - os indivíduos soberanos em um Estado soberano no sentido de Nietzsche -, justiça passa a ser um "comportamento positivo" inclusive para com aqueles que os prejudicam. Sob essa analogia compreendemos então o estreitamento entre graça e perdão. Em um apontamento póstumo à época de elaboração da Genealogia, Nietzsche escreve: "Nada se torna mais fácil para nós do que sermos sábios, pacientes, superiores, plenos de consideração, pacientes e simpáticos; de uma maneira absurda, somos para com tudo e todos desumanamente justos, nós perdoamos tudo. Perdoar: isso é precisamente nosso elemento." (Nachlass Outono 1887, 10[143], KSA 12, p. 536s.)

VIESENTEINER, Jorge Luiz; GOMES, Lucas Fraga. Nietzsche e Derrida em torno do pathos do perdão. Griot : 
A semântica do 'perdão' no apontamento póstumo tem de ser compreendida no sentido extramoral empregado por Nietzsche no texto publicado da Genealogia, ou seja, como "graça", autorizando-nos a aproximação da fórmula moral do perdão em um sentido extramoral da graça. A famosa formulação que resume esse processo de deslocamento, como se sabe, é autossupressão. A graça é, então, o privilégio do 'imoralista' ou do 'indivíduo soberano', aquele de tal modo supramoral que não encontra mais motivos nem sequer para reconciliar, ou mesmo para perdoar, pois da sua perspectiva o perdão perde seu sentido moral para se tornar 'graça'. $O$ limite do perdão como graça está ali onde a tradição moral em que ele ganha valor se torna na figura do 'imoralista' ou do 'indivíduo soberano' supramoral -, precisamente 'graça', sem encontrar seus equivalentes no interior da tradição moral contra a qual o imoralista ou o 'indivíduo soberano' se diferenciou. Nessa situação limítrofe, o perdão moralizado se autossuprime e não pode mais ser compreendido tal como normalmente o compreendemos, ou seja, por meio do seu horizonte moralizado; nesse limite, o perdão se torna pathos, um contraconceito à razão que igualmente não pode mais ser conceitualizado, registrado por Nietzsche, doravante, sob a rubrica de 'graça'.

Nem o 'imoralista' extramoral de ABM 32, nem o 'indivíduo soberano' supramoral de GM II 2 parecem ser analisados sob a rubrica de uma figura de pensamento que exprima qualquer reconciliação. Nesse ciclo heurístico da epocalização feito por Nietzsche, ambos os Typus não são o resultado final conciliador que exprimiria a suspensão ou suprassunção que tanto suprime quanto conserva, mas contínuo e ininterrupto processo de diferenciação. Se as proximidades com a dinâmica hegeliana podem saltar aos olhos nesse ponto, não se trata de compreender tal epocalização, contudo, em direção a qualquer Absoluto, o rumo da suspensão (Aufhebung) conciliatória dos momentos anteriores. É certo, porém, que Nietzsche, ao falar da 'graça' no aforismo 10 da 'Segunda Dissertação' de GM, empregando o termo em um sentido extramoral, serve-se do caro conceito hegeliano de Aufhebung, notadamente ao mencionar justiça e sua autossupressão.

$O$ deslocamento da epocalização histórica em detrimento da reconciliação, mas em proveito da diferenciação se justifica porque, mesmo no interior da GM, o 'indivíduo soberano' da Segunda Dissertação já estava associado ao Typus aristocrata, ao nobre [der Vornehme, der Mächtige, der Herrschende], no aforismo 11 da Primeira Dissertação (GM I 11; KSA 5, p. 274). Nobre é aquilo que não se deixa categorizar e, sobretudo, exprime-se como diferenciação em relação a qualquer vulgaridade (Gemeinheit), tal como a irreconciliável tensão explicada por Nietzsche entre Vornehmheit e Gemeinheit no capítulo nove de Para além de bem e mal intitulado precisamente "O que é nobre?" (sob a forma de uma interrogação). Tratase daquele "prazer nas nuances" (ABM 263) típico da reverência por si mesmo, do "instinto de reverência" por si mesmo, ou igualmente aquele "pendor de nobreza", como escreve Nietzsche nesse mesmo capítulo, "que destaca" "separa".

Caracterizar o aspecto da epocalização do 'indivíduo soberano' ou mesmo o 'imoralista' no registro da diferenciação e não da reconciliação, tal como é o caso da vinculação com o conceito de 'nobreza', apenas radicaliza os limites da moralização do perdão, desvelando-os, mas, simultaneamente, intensifica-se a impossibilidade de se utilizar o horizonte normalizador e calculativo do perdão moralizado, para avaliar

VIESENTEINER, Jorge Luiz; GOMES, Lucas Fraga. Nietzsche e Derrida em torno do pathos do perdão. Griot : 
uma figura de pensamento construída por Nietzsche sob o registro da supra ou extramoralidade. Graça é prerrogativa daquele novamente 'liberto da moral', do indivíduo supramoral. Estamos aqui no limiar das fragilidades da tratativa moralizante do perdão, como do perdão vinculado tradicionalmente à reconciliação, ou mesmo ao mero esquecimento conciliatório. Estamos justamente ali onde o horizonte supramoral já não mais permite nem sequer a dimensão moralizada/normalizada do perdão, e nem sua dimensão reconciliatória. No fundo, estamos ali onde o valor do valor moral perdão situa-se portanto como pathos, e não mais como moral.

Não se trata mais nesse caso de pensar o valor do valor perdão como busca pelo equivalente ao dano ou ao crime, tal como é o caso da justiça punitiva, - na medida em que perdoamos apenas se conseguimos punir por meio de um equivalente ao dano - nem mesmo pela rápida vinculação com a economia epocal da reconciliação, a saber, a epocalização que vai do diagnóstico culpa ou promessa quebrada no passado, passando pelo exercício do arrependimento no presente, até a perspectiva do perdão no futuro. Justamente esse substrato moralizante é que não mais sobrevive a uma epocalização diferenciadora, situada no registro da supra ou extramoralidade. Como pathos, o cálculo moralizado do perdão encontra seu limite, convertendo-se portanto em 'graça'.

Esse horizonte da autossupressão do valor moral do perdão em graça é um movimento que encontra ecos nas éticas contemporâneas, como por exemplo, a abordagem de Derrida sobre o tema do perdão. O filósofo, ao contrário de Nietzsche, emprega textualmente a palavra perdão nesse movimento extramoral. Passamos agora, então, para o segundo movimento do texto que é o estreitamento de Nietzsche com Derrida em torno do perdão.

\section{Segundo movimento: Derrida em torno do perdão Derrida, a herança de Nietzsche e a temática do perdão}

Cabe agora explicar como a tratativa de Derrida, especificamente em relação à temática do perdão, possui similitude com a proposta de Nietzsche.

É em sua obra Políticas da Amizade ${ }^{11}$ que se tem um dos testemunhos mais claros de Derrida em relação a influência que seu trabalho recebeu da filosofia de Nietzsche. Primeiramente, o autor demonstra como o filósofo alemão desestabilizou os conceitos filosóficos: "[...] quem terá nomeado melhor a nossa história, a nossa memória, a nossa cultura $[\ldots]$ a inverter, a contestar mesmo sua identidade elementar, a dissolver a sua irredutibilidade à análise" (DERRIDA, 2003b, p.89). Nota-se como esta postura também está presente na obra do filósofo franco-argelino, notadamente nas ferramentas da desconstrução e da differance, categorias que visam desestabilizar o hegemônico e que se cristalizaram em um processo - tal como era um dos objetivos do exercício genealógico em seu registro crítico de Nietzsche -, sempre na tentativa de escapar da lógica binomial. Especificamente nesta obra, que possui um caráter estritamente político e que Derrida procede uma desconstrução da amizade e sua relação com o político, o filósofo afirma que sua tratativa é uma

\footnotetext{
11 Para este trabalho foi utilizada a versão portuguesa com a tradução de Fernanda Bernardo
} 
desconstrução genealógica (DERRIDA, 2003b, p.117), claramente remetendo à ferramenta genealógica de Nietzsche.

Ainda nesse texto Derrida faz grande uso da expressão "filósofos por vir" (diese kommenden Philosophen) para se incluir neste processo e nesta herança: "Não pelo facto de virem, se vierem, no porvir, mas porque estes filósofos do porvir são já filósofos capazes de (pensar) o porvir, de trans-portarem e de suportarem o porvir, quer dizer, para o metafísico alérgico ao talvez, de aguentarem o intolerável, o indecidível e o terrificante [...]" (DERRIDA, 2003b, p. 50).

Para Derrida, assumir a herança de Nietzsche é assumir a contradição, a nuance, a aceitar a coexistência de valores contraditórios. Além disso, é fazer uso dos "conceitos-limite" tais como indecidível, decisão, impossível, etc. para desestabilizar as estruturas sedimentadas do conceito. Segundo o pensador, esta postura pode ser considerada como "louca" porém é só aí, no limite, que um pensamento é possível.

Na medida em que a filosofia de Derrida é antes de mais nada um emaranhado de "conceitos" que se avizinham, então temas como amizade, hospitalidade, justiça, decisão, sempre estão relacionados e passam a ser cada vez mais frequentes em sua obra a partir da década de 90. É durante essa época que o filósofo franco-argelino dedicou vários seminários sobre a questão do perdão e do perjúrio, defendendo a tese do perdão como a possibilidade do impossível, ou seja, para além daquilo que é calculável-moralizado, de modo que parece não ser forçoso afirmar que seu argumento é, em certa medida, herdeiro da maneira que Nietzsche aborda o tema da justiça/perdão/graça em Para genealogia da moral.

Derrida desconstrói os usos do perdão para demonstrar a forte herança abraâmica que tal conceito carrega, e sua utilização relaciona-se a certa filosofia de matriz hegeliana, especificamente relacionada à tese da reconciliação. Deve-se atentar que o processo de desconstrução nunca tem por objetivo a destruição, tratase antes de pensar um perdão que "escapasse às determinações do cristianismo, sem no entanto recusar de todo sua herança. Um perdão com a figura do Cristo e para além dela, com as culturas e religiões do perdão, sobretudo de origem abraâmica, e para além delas [...]" (NASCIMENTO, 2005, p.18).

A tarefa do filósofo franco-argelino tem no horizonte a possibilidade do perdão incondicional, ou seja, um perdão que perdoa até mesmo aquele que não lhe pede perdão. ${ }^{12}$ Esta dimensão do perdão possui uma estreita relação com o impossível, ou seja, o perdão, paradoxalmente, ganha sua dignidade plena como perdão no momento em que atinge sua impossibilidade, isto é, seu limite diante do cálculo normalizador: "[...] perdoar o imperdoável é fazer explodir a razão humana, ou pelo menos o princípio de razão interpretado como calculabilidade [...]" (DERRIDA; ROUDINESCO, 2004, p.197).

Ora, se falamos de incondicional, de imperdoável, de incalculável, logo estamos falando de uma esfera que está além do político, do direito e mesmo da

\footnotetext{
12 Vale lembrar nesse ponto de uma estreita conexão com o texto da Genealogia de Nietzsche: "Quando acontece que o homem justo permaneça justo até mesmo com aqueles que o prejudicam [...], quando a branda objetividade do olhar justo, do olhar bem ajustado, mas também elevado, claro e profundo não se turva nem sequer com a injúria pessoal, o escárnio e a calúnia, isso é então marca de perfeição e da mais elevada maestria" (GM II 11; KSA 5, p. 310s.).
}

VIESENTEINER, Jorge Luiz; GOMES, Lucas Fraga. Nietzsche e Derrida em torno do pathos do perdão. Griot : Revista de Filosofia, Amargosa, Bahia, v.16, n.2, p.352-370, dezembro/2017. 
moral. Em uma entrevista a Michel Wieviorka ${ }^{13}$, Derrida aponta que no campo político a utilização da linguagem do perdão nunca é pura e desinteressada. Ou seja, o filósofo convida a sempre duvidar quando um governo ou instituição perdoa alguém. Para Derrida, por trás desse ato existe uma intencionalidade, mesmo que seja por uma "boa razão".

Derrida constata que após a Segunda Guerra Mundial aconteceu uma "mundialização" do perdão, sendo este confundido com outros conceitos. Com isso, ele cria um neologismo a respeito deste fenômeno do perdão no mundo: a "mundiolatinização" do perdão, demonstrando aí o "efeito de cristianidade romana que sobre-determina atualmente toda a linguagem do direito, da política, e incluído a interpretação do chamado "retorno do religioso" [...] (DERRIDA, 2003a, p.12).

É justamente em contraposição a estes usos que o filósofo apresenta sua própria "definição" do perdão, ou seja, algo não normativo, algo extraordinário e que se põe à prova do impossível, ou ainda, o perdão enquanto um acontecimento que, enquanto tal, rompe a o curso ordinário da história:

[...] É talvez incluído o único que ocorra, que surpreenda, como uma revolução, o curso ordinário da história, da política e do direito. Porque isto quer dizer que segue sendo heterogêneo a ordem do político e do jurídico tal como são entendidos comumente. Jamais se poderia, neste sentido corrente das palavras, fundar uma política e um direito sobre o perdão. Em todas as cenas geopolíticas das que falávamos, se abusa da palavra "perdão". Porque sempre se trata de negociações mais ou menos declaradas, de transações calculadas, de condições e, como diria Kant, de imperativos hipotéticos [...] (DERRIDA, 2003a, p.19).

Derrida afirma que os dois polos, o do perdão como impossível e o perdão condicional, ou seja, aquele que se refere direta ou indiretamente a processos de reconciliação, são irredutíveis mas também indissociáveis. A questão é que é justamente este perdão puro, ou seja, o perdão enquanto impossível que possibilita, tensionalmente, as mudanças do cotidiano: “[...] Para modificar o curso da 'política" [...], para mudar o direito [...], é necessário referir-se ao que você acaba de chamar 'visão ética hiperbólica do perdão' [...] (DERRIDA, 2003a, p. 30). Desta forma, o filósofo sustenta a tese de que é justamente o perdão incondicional e a ideia do imperdoável que inspiraram os avanços no campo jurídico, tais como a criação dos crimes imprescritíveis bem como a criação do direito internacional e a instalação dos tribunais universais:

[...] para sempre, "eternamente", em qualquer parte e sempre, um crime contra a humanidade será passível de juízo, e jamais se esquecerá seu arquivo judicial. Para tanto, um certa idéia do perdão e do imperdoável, de um certo mais além do direito (de toda determinação histórica do direito), inspirou os legisladores e parlamentares, os que produzem o direito $[\ldots]$. Isto mostra claramente que, pese a sua aparência teórica, especulativa, purista, abstrata, toda reflexão sobre uma exigência incondicional está antecipadamente comprometida, e por completo, em um história concreta. Esta pode induzir, processos de transformação -

${ }^{13}$ El siglo y el perdon. Texto originalmente em espanhol. Tradução realizada pelos autores. 
política, jurídica - verdadeiramente sem limite. (DERRIDA, 2003a, p. 32s.).

É possível entender que ao relacionar o perdão com o impossível, Derrida está deixando sub-reptícia a "definição" do perdão como "acontecimento", ou seja, aquilo que "vem" e me surpreende, fugindo assim de qualquer horizonte do cálculo, da norma, da razão. É por isto que o filósofo por diversas vezes relaciona tal tratativa a uma loucura: “[...] há uma espécie de 'loucura' que o jurídico-político não pode abordar, menos ainda apropriar-se [...]" (DERRIDA, 2003a, p.34). Trata-se de uma ética além da ética ou como o próprio filósofo define, uma ética hiperbólica.

Compreende-se daí que o filósofo propõe uma noção de perdão enquanto pathos, sendo igualmente entendido como contraconceito da razão e, portanto, da mesma maneira como Nietzsche, um conceito que não pode ser estritamente conceitualizado, pois tão logo seja trazido à conceitualização, deixa de ser pathos e se transforma em cálculo, normalização, etc. Pensar o perdão como pathos se aproxima bastante da maneira como o filósofo pensou também a decisão. Deve-se ficar atendo, porém, que para Derrida uma autêntica decisão excede justamente os limites do cálculo: “[...] a decisão marca sempre a interrupção da deliberação jurídico - ou ético - ou político-cognitiva que a precede, e que deve precedê-la. O instante da decisão é uma loucura [...]" (DERRIDA, 2010, p. 52). Em outros termos, para Derrida uma autêntica decisão não lança mão de cálculos nem valorações, o puro ato de decidir é uma loucura visto que suspende os valores morais de orientação na vida, pois quando se questiona sobre sentido e normatividade, isso implica necessariamente em um agir. A tarefa que Derrida coloca é pensar a ação sob o signo da desontologização, ou seja, pensar as condições de possibilidade da ação (e consequentemente orientação) sem recorrer a subterfúgios tais como sujeito, verdade, vontade, livre arbítrio, etc. Dessa forma, o filósofo coloca-se na contramão de toda a história da ética. Derrida defende a tese que uma construção de sentido não trabalha com nada dado, ou seja, não se deve dizer como agir. Ou no máximo, não deve se fiar em pressupostos normativos como ferramentas orientadoras da ação, da decisão e mesmo do perdão. $O$ filósofo abre a possibilidade para uma ação que possui uma estreita relação com o inesperado e justamente devido a isto, o singular, referindo-se a um conceito moral sempre em seu sentido extramoral. Pensar o perdão enquanto acontecimento é diferenciá-lo do perdão condicional e mesmo da vingança - aquela típica da justiça punitiva carregada de ressentimento, como Nietzsche escreveu - visto que estes são previsíveis dentro do horizonte da ação.

\section{Derrida e a Comissão da Verdade e da Reconciliação}

A Comissão da Verdade e Reconciliação (doravante CVR) realizada na África do Sul foi o disparador que permitiu Derrida iniciar seus estudos sobre o perdão. A GVR foi instituída em 1995 pelo presidente Nelson Mandela e foi presidida pelo arcebispo anglicano Desmond Tutu. Apresentou um relatório em 1998 e concluiu os trabalhos em 2001. A CVR possuía a missão explícita de reconciliar uma país que sofreu por anos com o apartheid. Na CVR tornou-se o claro imbricamento do perdão com a temática teológica, política e jurídica:

VIESENTEINER, Jorge Luiz; GOMES, Lucas Fraga. Nietzsche e Derrida em torno do pathos do perdão. Griot : 
Era necessário estabelecer a verdade sobre os acontecimentos passados, a respeito dos motivos e circunstâncias dos atentados aos Direitos do Homem cometidos no quadro dos conflitos da era do apartheid e, daí, tirar as conclusões para evitar que esses atos se repetissem no futuro. A busca de uma unidade nacional, o bem-estar de todos os sul-africanos e a paz requeriam a reconciliação de diferentes comunidades do país e a reconstrução da sociedade. Esta tarefa se fundava sobre uma vontade de compreensão e não de vingança, de reparação e não de represálias, de auxílio fraterno (ubuntu) e não de vitimização. (MIGLIORI, 2009, p. 228).

Como dito anteriormente, o perdão não se refere a uma instituição, logo ele não se exerce no campo político. O político é um espaço em que todas as ações são calculadas, logo, interessadas, inviabilizando o perdão, visto que este, quando existe, aponta para o incalculável. Desta forma, no estilo "tensional" de sua proposta filosófica, a questão do perdão sempre se coloca entre uma ética hiperbólica do perdão e uma realidade dividida que está empenhada em processos de reconciliação (tal como ocorreu na África do Sul, na Argélia, na Bósnia, etc.).

Para Derrida, a linguagem do processo iniciado na África do Sul mascarava um forte desejo reconciliador de matriz hegeliana que consequentemente era uma forma de violência, visto que esse horizonte teleológico necessariamente era fonte de doutrinação cristã, exclusão (das mulheres sul-africanas, por exemplo) e violência (ao se solicitar publicamente às vítimas o relato da "verdade" dos episódios traumáticos). Logo, “[...] esse conceito cristão e dialético do perdão enquanto reconciliação exclui evidentemente a possibilidade do perjúrio, ou seja, o advento daquilo que não o garante de antemão como um acontecimento previsível. Como se, para Hegel, a história universal fosse promessa garantida de uma felicidade, de uma paz ou de uma liberação igualmente universal, pela superação do mal [...]" (NASCIMENTO, 2005, p. 21).

A desconstrução efetuada pelo filósofo demonstra que Tutu, mesmo que não intencionalmente, exerce uma certa violência. Para Derrida, isto já se coloca quando o bispo anglicano se propõe a traduzir as onze línguas sul-africanas para apenas uma: o inglês. Além disso, há que se observar que a figura de Cristo muitas vezes utilizadas na CVR por Tutu é estranha por grande parte da população sul-africana, que não são alinhadas religiosamente à matriz abraâmica. Por fim, Tutu também se atém a uma noção de perdão condicional, ou seja, existe uma finalidade em todo este teatro representado pelo bispo, seja a reconciliação, seja a redenção:

[...] Com essa referência equívoca a um perdão que não é nem rigorosamente dissociado do fenômeno jurídico-político da anistia nem simplesmente gratuito e incondicional, ele toma para si a tarefa de cristianizar sua argumentação. Tal cristianização não se efetua somente pelo deslizamento de uma tradução: a anistia se torna perdão, um perdão precedido de um testemunho acompanhado de arrependimento. A cristianização sub-reptícia é também, no decorrer do tornar-se-perdão da anistia, a imposição intentada de um modelo cristão do perdão. Este visa a sobrepujar outros modelos abraâmicos (judeus ou muçulmanos), ou outras formas de reconciliação ou de compaixão. Mais grave ainda, Tutu, como tantos outros, como a imensa maioria dos cristãos, se atém a um dos conceitos cristãos - e concorrentes - do perdão: ele privilegia o que prevalece amplamente nas tradições eclesiais e nas interpretações

VIESENTEINER, Jorge Luiz; GOMES, Lucas Fraga. Nietzsche e Derrida em torno do pathos do perdão. Griot : 
teológicas, a saber, o perdão condicional (em troca do arrependimento, do pedido de perdão, da transformação do pecador etc.), e ignora o perdão puro e incondicional, o que excede gratuitamente toda troca, todo pedido de perdão com arrependimento, reconciliação, conversão, redenção, toda economia, toda finalidade [...] (DERRIDA, 2005, p. 87).

Daí a importância que Derrida confere ao depoimento da viúva de uma vítima durante a CVR. Frente ao assassino de seu marido a mulher desautoriza toda a instituição e todo o governo, afirmando que apenas ela poderia perdoar, mas que, contudo, ela não estava pronta para isto. Derrida escreve então que a entrada em cena desta mulher é um acontecimento, que, como tal, abala as estruturas do teatro da reconciliação denunciando sua impostura: "Como avaliar tal acontecimento? Não tenho o menor acesso ao acontecimento de tradução que impôs a palavra 'perdoar' para restituir o que essa mulher queria dizer em sua língua. Ninguém tampouco pode ter acesso a seu sofrimento, a sua experiência, em seu corpo e lugar." (DERRIDA, 2005, p.75).

\section{Nietzsche e Derrida em torno do pathos do perdão}

Percebe-se que Derrida, ao pensar um perdão incondicional, ou seja, fora dos limites do político, do jurídico e do moral flerta muito de perto com a tese de Nietzsche que opera por diferenciação, com o objetivo de levar às últimas consequências uma determinada tradição moral ou conceito, de modo que ao cabo do seu desdobramento, termina por se autossuprimir. Nessa situação limítrofe, não somos mais autorizados a lançar mão do mesmo aparato normalizador para quaisquer avaliações, precisamente porque, nesse limite, os usos avaliativos estão na esfera da extramoralidade. Ora, a possibilidade do perdão em Derrida implica um horizonte que igualmente não lança mão de estratégias costumeiras, tal como a do castigo para o crime bem como da reconciliação para o arrependido, ou seja, está da mesma forma para além do binômio da justiça punitiva, e para além da economia histórica da reconciliação.

Voltemos agora às condições de possibilidade de tal perdão. É importante dizer que Derrida não resolve em definitivo essa questão, lançando apenas aporias que nos incitam a pensar novas possibilidades de ação e orientação sem os subterfúgios costumeiros (justiça, verdade, castigo, etc.). Retomemos então a referida entrevista concedida por Derrida. Já no final o filósofo afirma que um dos problemas da temática do perdão é justamente a questão da soberania, em uma clara alusão a Nietzsche:

[...] Imensa dificuldade, pois. Cada vez que o perdão é efetivamente exercido, parece supor algum poder soberano. Pode ser o poder soberano de uma alma nobre e forte, mas também o poder de um Estado que dispõe de uma legitimidade inquestionada, da potência necessária para organizar um processo, um juízo aplicável ou, eventualmente, a absolvição, a anistia ou o perdão [...] (DERRIDA, 2003a, p. 38).

Derrida explica que muitas vezes o discurso do perdão está engendrado em uma soberania, seja em um âmbito pessoal em que um sujeito perdoa um outro (mas

VIESENTEINER, Jorge Luiz; GOMES, Lucas Fraga. Nietzsche e Derrida em torno do pathos do perdão. Griot : 
com um olhar "de cima para baixo"), seja no âmbito político, quando nações ditas soberanas, detentoras de maior poder econômico e militar exercem o seu "perdão". Isso significa uma soberania no sentido violento do termo, e não soberania tal como aquela que explicamos anteriormente do 'indivíduo soberano' ou do 'Estado soberano', no sentido de Nietzsche.

Cabe agora interrogar o que Derrida quer dizer com alma nobre e forte capaz de perdoar, e a Genealogia de Nietzsche é novamente um importante auxílio. Em Para genealogia da moral, como vimos, Nietzsche de-moraliza o conceito de perdão, ou seja, um processo de autossupressão do valor moral que o conceito de perdão tradicionalmente recebeu, no interior da tradição reconciliatória em que se insere. Novamente, a tese da "autossupressão" é uma ferramenta conceitual fundamental para essa hipótese. Em termos específicos, então, trata-se de um

[...] movimento de inflexão no curso de um pensamento, ou numa cadeia de eventos históricos no mundo da cultura, operando uma mudança de sentido, uma decisiva alteração na direção, seja da sequência dos pensamentos, seja no desenrolar-se de um vir-a-ser dos fenômenos da cultura. Essa inflexão de sentido, ou mudança de direção caracteriza-se como uma volta contra si mesmo, uma reflexão, e nesse sentido, uma inversão de rota, um dobrar-se sobre si mesmo, tornado possível por problematização, ou seja, por um voltar-se para si mesmo (e contra si mesmo) do próprio sujeito ou de um processo histórico no interior do qual o primeiro se encontra, que, de diferentes maneiras, tomam a si mesmos como objeto - o que caracteriza, portanto, um movimento de (auto) problematização. (GIACOIA, 2010, p. 76).

O movimento da autossupressão se configura como uma experiência última em que ocorre um retorno e uma inversão, em que um conceito moral, p.ex., o conceito moral de perdão, é exposto em seu próprio limite moral, de modo a se autossuprimir tão logo se volta contra sua própria tradição e o valor que possui. Nessa situação limítrofe e já extramoral, somos forçados, por dever de honestidade, a tornarmo-nos igualmente 'imoralista' no sentido de Nietzsche. ${ }^{14}$ É justamente esse o desdobramento que ocorre com a justiça punitiva, partindo das mais originárias relações entre credor e devedor na esfera interpessoal, passando pela explicação dessas relações no âmbito da comunidade, do Estado, culminando em seu movimento de autossupressão, quando então o mecanismo da justiça punitiva se converte em "graça" para espíritos bem constituídos, como é o caso do "indivíduo soberano', inserido em um Estado soberano no sentido de Nietzsche.

Esse movimento na comunidade, no Estado, marca precisamente o alargamento da consciência de poder da comunidade, de modo que ela passa a se relacionar com o devedor de outra maneira: "Com o poder fortalecido, a comunidade não leva mais tão a sério os delitos do indivíduo, pois ela já não o considera mais como antes, perigoso e subversivo para a existência do todo" (GM II 10; KSA 5, p.

14 Sobre isso, Giacoia continua: "Ao fim do percurso, perguntamos pela crença que nos obriga, a nós imigrantes, que abandonamos para sempre o porto seguro da moral, a nos desobrigar do dever de obediência e seus imperativos. Justamente nessa crença se revela o engajamento moral da crítica da moral por Nietzsche: trata-se da esperança na possibilidade do além-do-homem, na abertura de novos horizontes para a aventura humana na história, de presságios que se delineiam à sombra terrificante do niilismo extremo." (GIACOIA JUNIOR, 2010, p.88) 
308). Precisamente o alargamento da consciência de poder alcançado da comunidade que permite, dentro dela mesmo, a autossupressão da justiça, cujo ponto de reversão se revela extramoral e passa então a ser denominada de graça em seu interior e nas mãos dos indivíduos soberanos: "A justiça que reivindicou que 'tudo é resgatável, tudo tem e ser pago' [...], termina como toda coisa boa sobre a terra, suprimindo-se a si mesma. Essa autossupressão da justiça: sabe-se com qual belo nome ela se autodenomina - graça; ela permanece, obviamente, o privilégio dos mais poderosos, ou melhor, seu além do direito." (GM II 10; KSA 5, p. 309)

Essa mesma passagem da Genealogia não passou despercebida por Derrida. Nas últimas páginas de sua obra Dar a Morte $^{15}$ ele afirma:

Porque Nietzsche vai mesmo ao ponto de ter em conta, se assim se pode dizer, o momento em que esta justiça integra o insolvente, o insaldável, o absoluto. Ele tem portanto em conta aquilo que transborda a economia como troca, e o comércio do re-conhecidamente. Ora, em vez de pôr isso no crédito da bondade pura, da fé, do dom infinito, Nietzsche detecta aí, ao mesmo tempo que a supressão do objeto, uma autodestruição da justiça em graça. (DERRIDA, 2013, p. 141). ${ }^{16}$

Derrida assume claramente aqui a posição nietzscheana da extramoralidade do perdão como graça. Na entrevista supracitada, Derrida diz que seu sonho é de alguma maneira um perdão incondicional que não faz uso da soberania no sentido pejorativo da justiça punitiva: "Com o que sonho, aquilo que tento pensar como a 'pureza' de um perdão digno desse nome, seria um perdão sem poder: incondicional, mas sem soberania. A tarefa mais difícil, mas necessária e aparentemente impossível, será então dissociar incondicionalidade e soberania [...]" (DERRIDA, 2003a, p. 38s.). Certamente devemos remontar nesse caso ao forte conceito nietzscheano de 'indivíduo soberano', a figura de pensamento que exprime tanto autossupressão quanto extramoralidade. Como vimos, o indivíduo soberano é soberano sobre si mesmo e não sobre outros, um Typus elaborado por Nietzsche que também igualmente não é resultado reconciliatório, mas de um processo de diferenciação. Avant la lettre, Nietzsche indica que não se trata necessariamente de desunir soberania e incondicionalidade, e sim, transvalorar os valores a tal ponto em que, além da moral, um indivíduo é soberano, ou nos termos de Derrida, a alma nobre e forte e capaz de perdoar.

Em suma, dois aspectos são similares na economia argumentativa de Nietzsche e Derrida: a de-moralização de um conceito no interior de uma tradição moral, como é o caso do valor moral perdão, e o distanciamento de uma tradição que

\footnotetext{
15 Para este trabalho foi utilizada a versão portuguesa com a tradução de Fernanda Bernardo.

${ }_{16}$ Um trabalho fundamental e digno de nota para o tema do perdão foi escrito por Paschoal (2011, p. 157), para quem essa projeção de Nietzsche não se configura como um projeto a se realizar na história. Trata-se de uma utopia do filósofo e que vislumbra a evolução do direito penal. Além disso, Giacóia afirma que mesmo com a violência mítica da pré-história da justiça, existe uma possibilidade de maturação deste processo que culmina no procedimento apresentado da autossuperação da justiça em graça: "Evidentemente, trata-se sempre de vontade de poder; mas sobretudo de sua transfiguração, de sua elevação a uma esfera cada vez mais efetivamente poderosa e consciente de poder, o que significa, ao mesmo tempo, que, em correspondência com essa consciência, prescinde da força bruta, da violência mítica." (GIACÓIA, 2010 , p. 105).
}

VIESENTEINER, Jorge Luiz; GOMES, Lucas Fraga. Nietzsche e Derrida em torno do pathos do perdão. Griot : 
insere o perdão na economia histórica da reconciliação. Se para a primeira semelhança a de-moralização opera pela radicalização do argumento até sua autossupressão - momento extramoral em que uma avaliação não se deixa mais subsumir à esfera política, jurídica ou moral -, na segunda semelhança a economia reconciliatória é reduzida em proveito de uma práxis de diferenciação. Nessa instância limítrofe, tanto para Nietzsche quanto para Derrida o perdão deixa de ser um conceito tratado na esfera estritamente moral, para ser pensado como pathos (resguardadas as peculiaridades de filosofemas nos autores), a prerrogativa daqueles genuinamente "soberanos" no sentido extramoral. E para retomarmos o que escrevemos no início do artigo, para além das peculiaridades e heranças entre Nietzsche e Derrida a propósito do 'estilo', parece-nos certamente fecundos outros experimentos teóricos, como esse do perdão. 


\section{Referências Bibliográficas}

BORN, M. "Nietzsches rhetorische Inszenierung der Psychologie". In: GEORG, J.; ZITTEL, C. (Hrsg.). Nietzsches Philosophie des Unbewussten. Berlin/Boston: Walter de Gruyter, 2012, pp. 197-206. Além disso, para uma relação entre crítica da cultura e ironizações,

DERRIDA, J. El siglo y el perdón. Fe y saber. 1ª Ed, Buenos Aires: Ediciones de la Flor, 2003a.

. Políticas da amizade. Trad. Fernanda Bernardo. Porto: Campo das Letras, 2003 b.

Força de lei: o fundamento místico da autoridade. 2nd Ed, São Paulo: Editora WMF

Martins Fontes, 2010.

Dar a morte. Trad. Fernanda Bernardo. Coimbra: Palimage, 2013.

DERRIDA, J.; ROUDINESCO, E. De que amanhã: diálogos. Rio de Janeiro: Jorge Zahar Ed., 2004.

"O perdão, a verdade, a reconciliação: qual gênero?" In: Jacques Derrida: pensar a desconstrução. NASCIMENTO, E. (org.). Trad. Evando Nascimento. São Paulo: Estação Liberdade, 2005.

GIACOIA JÚNIOR, O. "Zu Nietzsches Satz 'autonom und sittlich schliesst sich aus" . In: Nietzsche-Studien, v. 40 (2011), pp. 156-177

"A autossupressão como catástrofe da consciência moral." In: Estudos Nietzsche, Curitiba, v.1, p.73-128, jan./jun. 2010. 319-324.

"Kulturkritik und Satyrspiel bei Nietzsche". In: Nietzscheforschung v. 23 (2016), pp.

HÖFFE, O. "Ein Thier heranzüchten, das versprechen darf". In: HÖFFE, O. (Hrsg.). Zur Genealogie der Moral. Bd. 29. Berlin: Akademie Verlag, 2004. pp. 65-79

MIGLIORI, M. L. B. Horizontes do perdão: reflexões a partir de Paul Ricoeur e Jacques Derrida. São Paulo: EDUC; FAPESP, 2009.

NASCIMENTO, E. "O perdão, o adeus e a herança em Derrida. Atos de memória". In: Jacques Derrida: pensar a desconstrução. NASCIMENTO, E. (org.). Trad. Evando Nascimento. São Paulo: Estação Liberdade, 2005.

NIETZSCHE, F. Sämtliche Werke. Kritische Studienausgabe in 15 Bänden. (KSA) Hrsg. Giorgio Colli und Mazzino Montinari. Berlin/New York: DTV \& Walter de Gruyter, 1999.

SAAR, M. Genealogie als Kritik. Geschichte und Theorie des Subjekts nach Nietzsche und Foucault. Frankfurt/New York: Campus Verlag, 2007.

STEGMAIER, Werner. Nietzsches „Genealogie der Moral“, Darmstadt: WGB, 1994

PASCHOAL, A. “Nietzsche e Dühring: Ressentimento, Vingança e Justiça”. Dissertatio. vol. 33, p. 147-172, 2011.

VIESENTEINER, Jorge L. "Estrutura formal e semântica do argumento autogenealógico". In: Cadernos de filosofia alemã v. 20, n. 2 (2015), pp. 105-119.

Contribuição dos autores:

O artigo foi redigido, discutido e revisado pelos autores Jorge Luiz Viesenteiner e Lucas Fraga Gomes. Ambos aprovaram a sua versão final.

Autor(a) para correspondência: Jorge Luiz Viesenteiner, Universidade Federal do Espírito Santo, Centro de Ciências Humanas e Naturais, Av. Fernando Ferrari, 514, Goiabeiras, CEP 29075-910, Vitória - ES, Brasil. jvies@uol.com.br 